\title{
A Family History of Diabetes Modifies the Association between Elevated Urine Albumin Concentration and Hyperglycemia in Nondiabetic Mexican Adolescents
}

\author{
Aida Jiménez-Corona, ${ }^{1,2}$ Antonio Ávila-Hermosillo, ${ }^{3}$ \\ Robert G. Nelson, ${ }^{4}$ and Guadalupe Ramírez-López ${ }^{5}$ \\ ${ }^{1}$ General Directorate of Epidemiology, Health Secretariat, Francisco P Miranda 177, Colonia Lomas de Plateros, \\ Delegación Álvaro Obregón, 01480 Mexico City, DF, Mexico \\ ${ }^{2}$ Ocular Epidemiology Department, Institute of Ophthalmology Foundation Conde of Valenciana, IAP, Chimalpopoca 14, \\ Colonia Obrera, Delegación Cuauhtémoc, 06800 Mexico City, DF, Mexico \\ ${ }^{3}$ Regional General Hospital No. 89, Mexican Institute of Social Security, Washington 1988, Colonia Moderna, Sector Juárez, \\ 44150 Guadalajara, JAL, Mexico \\ ${ }^{4}$ Diabetes Epidemiology and Clinical Research Section, National Institute of Diabetes and Digestive and Kidney Diseases, \\ Phoenix Epidemiology and Clinical Research Branch, 1550 East Indian School Road, Phoenix, AZ 85014, USA \\ ${ }^{5}$ Adolescent Epidemiological and Health Services Research Unit, Mexican Institute of Social Security, Avenida Tonalá 121, \\ 45400 Guadalajara, JAL, Mexico
}

Correspondence should be addressed to Guadalupe Ramírez-López; maria.ramirezlo@imss.gob.mx

Received 18 March 2015; Accepted 8 July 2015

Academic Editor: Hiroshi Okamoto

Copyright (C) 2015 Aida Jiménez-Corona et al. This is an open access article distributed under the Creative Commons Attribution License, which permits unrestricted use, distribution, and reproduction in any medium, provided the original work is properly cited.

We examined the frequency of elevated urine albumin concentration (UAC) and its association with metabolic syndrome (MetS) and metabolic markers in 515 nondiabetic Mexican adolescents stratified by family history of diabetes (FHD). UAC was measured in a first morning urine sample and considered elevated when excretion was $\geq 20 \mathrm{mg} / \mathrm{mL}$. MetS was defined using International Diabetes Federation criteria. Fasting insulin, insulin resistance, and lipids were evaluated. Multivariate logistic regression was performed. Elevated UAC was present in $12.4 \%$ and MetS was present in $8.9 \%$ of the adolescents. No association was found between elevated UAC and MetS. Among adolescents with FHD, 18.4\% were overweight and 20.7\% were obese, whereas, among those without a FHD, $15.9 \%$ were overweight and $7.5 \%$ were obese. Hyperglycemia was higher in those with elevated UAC than in those without $(44.4 \%$ versus $5.1 \%, p=0.003)$. Hyperglycemia $(\mathrm{OR}=9.8,95 \% \mathrm{CI} 1.6-59.4)$ and number of MetS components $(\mathrm{OR}=4.5$, 95\% CI 1.5-13.3) were independently associated with elevated UAC. Among female participants, abdominal obesity was associated with elevated UAC $(\mathrm{OR}=4.5,95 \% \mathrm{CI} 1.2-16.9)$. Conclusion. Elevated UAC was associated neither with MetS nor with any metabolic markers in nondiabetic adolescents. However, FHD modified the association of elevated UAC with hyperglycemia and the number of MetS components.

\section{Introduction}

Microalbuminuria is a marker of systemic endothelial dysfunction [1]. In the general population, it predicts multiple outcomes, including type 2 diabetes, hypertension, chronic kidney and cardiovascular diseases, metabolic syndrome (MetS), and all-cause, cardiovascular, and renal mortality
[2-5]. During puberty, microalbuminuria may be present as a consequence of changes in renal hemodynamics, insulin resistance, sexual hormones, somatic growth, and the reninangiotensin-aldosterone system [6].

The prevalence of microalbuminuria varies with age in nondiabetics, ranging from $6.5 \%$ to $8.9 \%$ in children and adolescents $[7,8]$, from $4.4 \%$ to $5.9 \%$ in young adults $[9,10]$, 
and from $7.7 \%$ to $22.0 \%$ in older adults [9]. The prevalence of MetS is between $4.5 \%$ and $6.7 \%$ in adolescents, depending on the criteria used $[11,12]$, and it is higher in MexicanAmericans and Mexicans (10.4\% to $19.6 \%$ ) than in nonHispanic whites $[12,13]$ and in the presence of obesity $(32.8 \%)$ [11].

According to the WHO criteria, microalbuminuria is part of the MetS [14], although no other definitions of MetS include it $[11-13,15]$. Hypertension, high glucose, high triglycerides, and abdominal obesity are related to microalbuminuria in adults $[4,16]$, but these relationships are not clear in adolescents. Some investigators have found no association between MetS and microalbuminuria in adolescents [8, 17], whereas others have reported an association among obese adolescents $[18,19]$.

We examined the frequency of elevated urine albumin concentration (UAC) in nondiabetic Mexican adolescents and its association with MetS and metabolic markers. We also examined these associations after stratifying by the family history of diabetes, since having a first-degree relative with diabetes appears to increase the risk of elevated albuminuria [20].

\section{Materials and Methods}

2.1. Study Population. A cross-sectional study was conducted in public high-schools in the suburbs of Guadalajara, Jalisco, Mexico. Study participants included 15-19-year-old adolescents who consented to participate and reported that they were unaware of having any chronic disease. Of the 654 adolescents enrolled in the first year of high-school, 570 $(87.2 \%)$ agreed to participate in the study. Fifty-five were excluded from the study because of missing data (anthropometric measurements or blood or urine samples). There were no differences between participants and nonparticipants for age (mean $=16$ years in both groups), body mass index (BMI) (21.8 versus $\left.21.6 \mathrm{~kg} / \mathrm{m}^{2}, p=0.758\right)$, menstruation status $(98.4 \%$ versus $97.6 \%, p=0.537)$, or smoking $(5.4 \%$ versus $9.5 \%, p=0.183)$. More boys than girls participated in the study $(51.0 \%$ versus $49.0 \%, p=0.016)$. The protocol was approved by the Institutional Review Board of the Mexican Institute of Social Security and designed based on the Declaration of Helsinki. Written informed assent/consent was obtained from all of the students and their parents.

2.2. Measurements. Data (questionnaires and anthropometric and blood pressure measurements) were collected at the schools by trained nutritionists, using standardized procedures. Height, weight, waist circumference, and triceps and subcapsular skin-fold thickness were measured by the Lohman method [21]. Blood pressure was measured using a validated digital Baumanometer (Omron HEM-751; Vernon Hills, IL, USA), after the participant was seated for $5 \mathrm{~min}$, and the average of two measurements was obtained.

A blood sample was obtained after a 12-hour fast by venipuncture and frozen at $-80^{\circ} \mathrm{C}$ until analyzed. Serum glucose concentration was measured using a hexokinase automated method (Synchron CX4, Beckman Coulter Inc.,
Brea, CA, USA). Serum insulin concentration was measured using an IMMULITE 2000 analyzer (Diagnostic Products Co., Los Angeles, CA, USA) and a solid-phase, two-site chemiluminescent immunometric assay. Insulin resistance was evaluated using the homeostatic model assessment index of insulin resistance (HOMA-IR) calculated as

$$
\frac{\text { fasting insulin }(\mu \mathrm{U} / \mathrm{mL}) \times \text { fasting glucose }(\mathrm{mmol} / \mathrm{L})}{22.5} \text {. }
$$

Serum triglyceride concentrations were determined using conventional enzymatic procedures. Total serum cholesterol, low-density lipoprotein-cholesterol (LDL-C), and high-density lipoprotein-cholesterol (HDL-C) concentrations were determined using immunochemical methods and an ILab 300 Plus analyzer (Instrumentation Laboratory Ltd., Birchwood, Warrington, UK).

A single-void first morning urine sample was collected and kept at $2-8^{\circ} \mathrm{C}$ for less than two weeks, until analysis was performed. Adolescents were asked not to perform exercise the day before samples were taken. In girls, urine samples were collected at least 3 days before or 3 days after menstruation. Urine albumin concentration (UAC) was measured using radioimmunoassay and double antibody albumin (Diagnostic Products Co., Los Angeles, CA, USA). In this competitive radioimmunoassay, ${ }^{125}$ I-labeled albumin competes with albumin in the patient sample for antibody binding sites.

2.3. Outcome Variable. Urine albumin concentration was classified as normal if it was $<20 \mathrm{mg} / \mathrm{mL}$ and elevated when it was $\geq 20 \mathrm{mg} / \mathrm{mL}[22]$.

2.4. Independent Variables. MetS was defined according to the International Diabetes Federation criteria. For adolescents who were 10-16 years old, MetS includes abdominal obesity (waist circumference $\geq 90$ th percentile for age and sex) and two or more of the following: fasting glucose $\geq 5.6 \mathrm{mmol} / \mathrm{L}(100 \mathrm{mg} / \mathrm{dL})$; triglycerides $\geq 1.7 \mathrm{mmol} / \mathrm{L}$ $(150 \mathrm{mg} / \mathrm{dL})$; HDL-C $<1.3 \mathrm{mmol} / \mathrm{L}$ (40 mg/dL); and systolic blood pressure $\geq 130 \mathrm{~mm} \mathrm{Hg}$ or diastolic blood pressure $\geq 85 \mathrm{~mm} \mathrm{Hg}$. For adolescents who were more than 16 years old, MetS includes abdominal obesity (waist circumference $\geq 90 \mathrm{~cm}$ for boys and $\geq 80 \mathrm{~cm}$ for girls) and two or more of the following: glucose $\geq 5.6 \mathrm{mmol} / \mathrm{L}(100 \mathrm{mg} / \mathrm{dL})$; triglycerides $\geq 1.7 \mathrm{mmol} / \mathrm{L}$ (150 mg/dL); HDL-C $<1.0 \mathrm{mmol} / \mathrm{L}(40 \mathrm{mg} / \mathrm{dL})$ for boys and $<1.3 \mathrm{mmol} / \mathrm{L}(50 \mathrm{mg} / \mathrm{dL})$ for girls; and systolic blood pressure $\geq 130 \mathrm{~mm} \mathrm{Hg}$ or diastolic blood pressure $\geq 85 \mathrm{~mm} \mathrm{Hg}$ [15].

High total serum cholesterol concentration was defined as $\geq 5.2 \mathrm{mmol} / \mathrm{L}(200 \mathrm{mg} / \mathrm{dL})$ and high LDL-C as $\geq 3.4 \mathrm{mmol} / \mathrm{L}$ $(130 \mathrm{mg} / \mathrm{dL})$, in accordance with the National Cholesterol Education Program criteria [23]. High insulin concentration was defined as $\geq 90.3 \mathrm{pmol} / \mathrm{L}(15.05 \mu \mathrm{U} / \mathrm{mL})$ and a high HOMA-IR value was defined as $\geq 3.43$ [24].

Overweight and obesity were defined according to the International Obesity Task Force BMI criteria that established BMI cutoffs for age and sex corresponding to values of $25 \mathrm{~kg} / \mathrm{m}^{2}$ for overweight and $30 \mathrm{~kg} / \mathrm{m}^{2}$ for obesity at 18 years 
of age [25]. An estimate of the percent body fat was calculated using sex-specific Slaughter equations for the sum of triceps and subscapular skin-folds ( $\leq 35 \mathrm{~mm}$ or $>35 \mathrm{~mm}$ ) according to Tanner stages (prepubertal, pubertal, or postpubertal stage) [26].

Family history of type 2 diabetes, which was obtained by a questionnaire delivered to parents, was considered to be positive if at least one of the parents had diabetes.

2.5. Covariables. Smoking and physical activity habits were obtained by interview using a standardized questionnaire. Smoking was defined as minimum of one cigarette smoked per day during the past month [27]. A physical activity and inactivity questionnaire validated in Mexican children was used to estimate the total hours per day of physical activity performed during the last month, and summarize responses according to the intensity of exercise (light, moderate, or vigorous) [28]. A semiquantitative food-frequency questionnaire [29] estimated the participant's daily average intakes of energy and macronutrients using the Evaluation System of Nutritional Habits and Nutrient Intake (ESNUT). Pubertal development was evaluated according to the Tanner stages using an autoadministered questionnaire that showed photographs and detailed descriptions for each of the five stages (from prepubertal to complete puberty) [30].

2.6. Statistical Analysis. Descriptive analysis included the calculation of means, standard deviations, medians, and percentages. Mean differences were estimated using Student's $t$ test for independent normally distributed samples and using Wilcoxon rank-sum test for median differences when the distributions were skewed. Chi-square tests or Fisher's exact test was used to evaluate percentage differences. Crude and adjusted logistic regression analyses were used to evaluate the association between elevated UAC and MetS (or metabolic components). Multivariate logistic regression models were adjusted for sex (male/female), sexual development (IIIV/V), family history of diabetes (yes/no), smoking (yes/no), percent body fat (\%), total physical activity (h/day), and protein intake (g/day). Interactions between family history of diabetes and MetS or metabolic markers were evaluated. Subsequently, unadjusted and adjusted logistic regression models were also evaluated after stratifying by family history of diabetes. A Hosmer-Lemeshow test grouped according to deciles of risk was used to evaluate goodness of fit. Stata 9.0 (Stata Corporation, TX) was used for statistical analysis and $p<0.05$ was considered to be statistically significant.

\section{Results}

A total of 515 nondiabetic adolescents participated in the study. The prevalence of elevated UAC in this cohort was $12.4 \%$. In adolescents with elevated UAC $(\geq 20 \mathrm{mg} / \mathrm{mL})$, the UAC median (percentiles 25-75) was $27.5 \mathrm{mg} / \mathrm{mL}$ $(23.3-38.0 \mathrm{mg} / \mathrm{mL})$, and, in those without elevated UAC $(<20.0 \mathrm{mg} / \mathrm{mL})$, the UAC median was $6.4 \mathrm{mg} / \mathrm{mL}(3.2-$ $10.0 \mathrm{mg} / \mathrm{mL}$ ). The prevalence of MetS was $8.9 \%$. Among the participants, $31.7 \%$ had no MetS components (including abdominal obesity), $45.1 \%$ had one component, $13.4 \%$ had two components, and $9.9 \%$ had three or more components. Low HDL-C concentration was present in $58.5 \%$ of the participants, abdominal obesity in $15.3 \%$, high triglyceride concentrations in $14.0 \%$, high serum glucose concentration in $9.5 \%$, and high blood pressure in $7.8 \%$. The prevalence of high total serum cholesterol concentration was $7.6 \%$, high LDL-C concentration was $10.1 \%$, high fasting insulin concentration was $15.8 \%$, and high insulin resistance was $13.8 \%$.

The sociodemographic and clinical characteristics according to UAC group are shown in Table 1. Waist circumference and percent body fat were lower in adolescents with elevated UAC than in those without elevated UAC (waist circumference $=72.0 \pm 7.6 \mathrm{~cm}$ versus $75.6 \pm 10.4 \mathrm{~cm}$, $p=0.021$; percent body fat $=26.5 \pm 9.9 \%$ versus $29.9 \pm 11.9 \%$, $p=0.026$ ). Although the frequency of hyperglycemia was higher in adolescents with elevated UAC than in those with normal UAC ( $12.5 \%$ versus $9.1 \%, p=0.384)$, this difference was not statistically significant. None of the other variables differed between UAC groups.

The relationships between elevated UAC and MetS components and other metabolic markers were examined according to the presence or absence of a family history of diabetes (Table 2). Among adolescents without a family history of diabetes $(n=422)$, waist circumference remained lower in the group with elevated UAC than in the normal UAC group $(71.0 \pm 6.9 \mathrm{~cm}$ versus $74.9 \pm 10.3 \mathrm{~cm}, p=0.013)$, but the difference in percent body fat, although numerically similar, was no longer statistically significant $(26.4 \pm 8.9 \%$ versus $28.9 \pm 11.1 \%, p=0.120)$. Among adolescents with a family history of diabetes $(n=87)$, the proportion with high serum glucose concentration was higher in the group with elevated UAC than in the normal UAC group (44.4\% versus $5.1 \%, p=0.003)$. Neither MetS nor other metabolic markers differed according to UAC group in those with or without a family history of diabetes.

Elevated UAC in the entire cohort was unrelated to MetS or any metabolic markers after adjustment for sex, level of sexual development, smoking, physical activity, protein intake, percent body fat, or family history of diabetes by logistic regression analysis (Table 3). Similar results were found when analyses were performed separately in adolescents who were obese and in those who were not (Table 4).

A strong interaction was found, however, between family history of diabetes and hyperglycemia $(p=0.003)$, so multivariate logistic regression analyses were performed after stratifying by family history of diabetes (Table 5). Among adolescents with a family history of diabetes, hyperglycemia $(\mathrm{OR}=9.81,95 \%$ CI $1.62-59.43)$, and the number of MetS components (OR $=4.48,95 \%$ CI 1.51-13.32) were independently associated with elevated UAC in comparison to normal UAC after controlling for covariates. No other statistically significant associations were found according to family history of diabetes. As no males had abdominal obesity along with elevated UAC, the association between these two parameters was only evaluated in females and was statistically significant $(\mathrm{OR}=4.5,95 \%$ CI 1.2-16.9). 
TABLE 1: Sociodemographic and clinical characteristics by urine albumin concentration group.

\begin{tabular}{|c|c|c|c|}
\hline Sociodemographic and clinical characteristic & \multirow{2}{*}{$\begin{array}{c}\text { Normal UAC } \\
(n=451)\end{array}$} & \multirow{2}{*}{$\begin{array}{c}\begin{array}{c}\text { Elevated UAC } \\
(n=64)\end{array} \\
56.3\end{array}$} & \multirow{2}{*}{$\frac{p \text { value }^{\ddagger}}{0.199}$} \\
\hline Female (\%) & & & \\
\hline \multirow{2}{*}{ Age (years) } & $16.6 \pm 0.9$ & $16.6 \pm 1.0$ & \multirow{2}{*}{0.795} \\
\hline & $16.0(16.0,17.0)$ & $16.5(16.0,17.0)$ & \\
\hline \multirow{2}{*}{ Tanner sexual stages (\%) } & 66.5 & 78.1 & \multirow{2}{*}{0.063} \\
\hline & 33.5 & 21.9 & \\
\hline Smoking (\%) & 5.8 & 3.2 & 0.559 \\
\hline Family history of diabetes (\%) & 12.8 & 10.3 & 0.527 \\
\hline \multirow{2}{*}{ Physical activity (h/day) } & $2.2 \pm 1.0$ & $2.2 \pm 1.0$ & \multirow{2}{*}{0.934} \\
\hline & $2.0(1.5,2.8)$ & $2.1(1.4,2.8)$ & \\
\hline \multirow{2}{*}{ Protein intake (g/day) } & $87.2 \pm 36.1$ & $85.5 \pm 28.8$ & \multirow{2}{*}{0.909} \\
\hline & $80.3(64.5,100.3)$ & $78.8(62.8,105.5)$ & \\
\hline \multirow{2}{*}{ Body mass index $\left(\mathrm{kg} / \mathrm{m}^{2}\right)$} & $22.8 \pm 4.4$ & $21.8 \pm 3.7$ & \multirow{2}{*}{0.057} \\
\hline & $22.0(19.7,24.9)$ & $20.9(19.4,23.0)$ & \\
\hline \multirow{4}{*}{$\begin{array}{l}\text { Low weight } \\
\text { Normal weight } \\
\text { Overweight } \\
\text { Obese }\end{array}$} & 8.0 & 9.4 & \multirow{4}{*}{0.479} \\
\hline & 65.0 & 71.9 & \\
\hline & 16.9 & 14.1 & \\
\hline & 10.2 & 4.7 & \\
\hline \multirow{2}{*}{ Waist circumference $(\mathrm{cm})$} & $75.6 \pm 10.4$ & $72.0 \pm 7.6$ & \multirow{2}{*}{0.021} \\
\hline & $73.4(68.3,80.7)$ & $71.0(66.7,76.1)$ & \\
\hline \multirow{2}{*}{ Percent body fat (\%) } & $29.8 \pm 11.4$ & $26.5 \pm 9.9$ & \multirow{2}{*}{0.026} \\
\hline & $29.9(28.5,30.9)$ & $25.9(21.9,30.0)$ & \\
\hline Abdominal obesity (\%) & 16.0 & 10.9 & 0.296 \\
\hline \multirow{2}{*}{ Fasting glucose $(\mathrm{mmol} / \mathrm{L})$} & $4.91 \pm 6.43$ & $4.93 \pm 0.42$ & \multirow{2}{*}{0.597} \\
\hline & $4.88(4.55,5.27)$ & $4.88(4.61,5.27)$ & \\
\hline High glucose (\%) & 9.1 & 12.5 & 0.384 \\
\hline \multirow{2}{*}{ Fasting insulin (pmol/L) } & $64.2 \pm 31.8$ & $57.0 \pm 22.8$ & \multirow{2}{*}{0.132} \\
\hline & $56.4(43.2,76.8)$ & $49.8(41.4,69.0)$ & \\
\hline High insulin (\%) & 16.7 & 9.4 & 0.134 \\
\hline HOMA-IR & $2.3 \pm 1.3$ & $2.1 \pm 0.9$ & 0.199 \\
\hline & $2.0(1.5,2.9)$ & $1.9(1.5,2.6)$ & \\
\hline High HOMA-IR (\%) & 14.4 & 9.4 & 0.271 \\
\hline Systolic blood pressure ( $\mathrm{mm} \mathrm{Hg}$ ) & $113.1 \pm 9.9$ & $111.4 \pm 12.0$ & 0.237 \\
\hline systonc oivod pressure (inm 11g) & $112.5(105.5,120.0)$ & $109.8(104.3,119.5)$ & 0.231 \\
\hline Diastolic blood pressure $(\mathrm{mm} \mathrm{Hg})$ & $68.9 \pm 8.7$ & $67.6 \pm 7.7$ & 0.261 \\
\hline Diastolic blood pressure (mm Hg) & $68.5(63.0,74.5)$ & $67.0(62.3,72.9)$ & 0.201 \\
\hline High blood pressure (\%) & 8.0 & 6.3 & 0.628 \\
\hline Triglycerides (mmol/L) & $1.3 \pm 0.8$ & $1.2 \pm 0.6$ & 0.476 \\
\hline Iriglycerıdes (mmol/L) & $1.1(0.8,1.5)$ & $1.0(0.8,1.3)$ & $0.4 / 6$ \\
\hline High triglycerides $(\%)$ & 14.6 & 9.4 & 0.256 \\
\hline Total cholesterol (mmol/L) & $4.0 \pm 0.9$ & $3.8 \pm 0.7$ & 0.137 \\
\hline 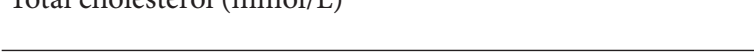 & $3.9(3.4,4.5)$ & $3.8(3.3,4.3)$ & \\
\hline High total cholesterol (\%) & 8.0 & 4.7 & 0.455 \\
\hline $\mathrm{HDL}-\mathrm{C}(\mathrm{mmol} / \mathrm{L})$ & $1.1 \pm 0.2$ & $1.1 \pm 0.2$ & 0.957 \\
\hline $\mathrm{HDL}-\mathrm{C}(\mathrm{mmol} / \mathrm{L})$ & $1.1(0.9,1.2)$ & $1.1(0.9,1.2)$ & 0.031 \\
\hline Low HDL-C (\%) & 57.4 & 65.6 & 0.213 \\
\hline
\end{tabular}


TABLE 1: Continued.

\begin{tabular}{|c|c|c|c|c|}
\hline \multicolumn{2}{|c|}{ Sociodemographic and clinical characteristic } & $\begin{array}{c}\text { Normal UAC } \\
\quad(n=451)\end{array}$ & $\begin{array}{c}\text { Elevated UAC } \\
\quad(n=64)\end{array}$ & $p$ value $^{\ddagger}$ \\
\hline \multirow{2}{*}{\multicolumn{2}{|c|}{$\mathrm{LDL}-\mathrm{C}(\mathrm{mmol} / \mathrm{L})$}} & $2.5 \pm 0.7$ & $2.4 \pm 0.6$ & \multirow{2}{*}{0.330} \\
\hline & & $2.5(2.1,2.9)$ & $2.4(2.0,2.8)$ & \\
\hline High LDL-C (\%) & & 10.2 & 9.4 & 0.838 \\
\hline MetS (\%) & & 9.3 & 6.3 & 0.638 \\
\hline \multirow{4}{*}{ Number of MetS components ${ }^{\mathrm{b}}(\%)$} & 0 & 32.6 & 25.0 & \multirow{4}{*}{0.408} \\
\hline & 1 & 43.7 & 54.7 & \\
\hline & 2 & 13.5 & 12.5 & \\
\hline & 3 & 10.2 & 7.8 & \\
\hline
\end{tabular}

Values are means \pm standard deviation, medians (25th percentile, 75 th percentile), or percentage.

HDL-C: high-density lipoprotein-cholesterol, HOMA-IR: insulin resistance, LDL-C: low-density lipoprotein-cholesterol, MetS: metabolic syndrome, and UAC: urine albumin concentration.

${ }^{\ddagger}$ Chi square test, Fisher's exact test, Student's $t$-test, or Wilcoxon rank sum test.

${ }^{a}$ HOMA-IR: fasting insulin $(\mu \mathrm{U} / \mathrm{mL}) \times$ fasting glucose $(\mathrm{mmol} / \mathrm{L}) / 22.5$.

${ }^{\mathrm{b}}$ Including abdominal obesity.

\section{Discussion}

In nondiabetic Mexican adolescents, elevated UAC was not associated with MetS or with metabolic markers. These findings are consistent with other studies in adolescents $[8,17]$, but they contradict findings in obese nondiabetic children [19]. Inconsistencies between studies may be due, in part, to the choice of MetS criteria used in the studies or due to other differences in the populations. Peralta et al. [31], for example, found that among Hispanics residing in the United States, Native American ancestry was associated with a higher prevalence of elevated albuminuria than European ancestry. Additionally, they found that the prevalence of elevated albuminuria was attenuated by higher socioeconomic status. The prevalence of elevated UAC in our study was similar to albuminuria found in the Mexican-American adults in their study.

Microalbuminuria in nondiabetic adolescents and adults has previously been associated with hyperinsulinemia, glucose intolerance, hypertension, or hypercholesterolemia [8, $17,18,32]$. We report for the first time that fasting hyperglycemia and the number of MetS components are associated with elevated UAC in nondiabetic Mexican adolescents, but only among those with a family history of diabetes. This finding is consistent with the observations from the Mexico City Diabetes Study, in which microalbuminuria was associated with parental history of diabetes and impaired glucose tolerance in nondiabetic Mexican adults [33].

Persons with elevated albuminuria and impaired glucose tolerance are at increased risk for developing type 2 diabetes [5, 33-35]. In the Framingham study, an association between microalbuminuria and hyperglycemia was found 24 years before the diagnosis of type 2 diabetes [34], and the prevalence of microalbuminuria increased with the increasing glycemia even before the onset of diabetes [35]. Furthermore, in adults, family history of diabetes has been recognized as an independent risk factor for type 2 diabetes [36, 37]. In children and adolescents from the Bogalusa Heart Study, parental history of diabetes was the most important risk factor to predict type 2 diabetes (hazard ratio $=2.67,95 \%$ CI 1.58-4.53) [38] and in the TODAY study almost $90 \%$ of diabetic American adolescents had a family history of diabetes (including nuclear family and grandparents) [39]. The association of elevated UAC with fasting hyperglycemia among adolescents with a family history of diabetes in the present study suggests that these adolescents are at greater risk for diabetes later in life.

We found that abdominal obesity was associated with elevated UAC only among female adolescents in the total population. In nondiabetic adults, abdominal obesity has been found to be an independent risk factor for microalbuminuria [4], although this was not observed in the Mexico City Diabetes Study [33] and other studies in Venezuelan adults [40]. On the other hand, obesity was independently associated with microalbuminuria in nondiabetic South Asian adults with type 2 diabetic relatives [41]. The same inconsistencies have been observed in adolescents; Hungarians showed a higher urinary albumin/creatinine ratio among obese versus nonobese; however, the difference was not controlled by confounders [18]. On the other hand, in a national sample of adolescents from the United States, the prevalence of microalbuminuria was lower among obese than nonobese [8]. Also, BMI and \% body fat were not different by microalbuminuria status in obese children and adolescents [17]. The mechanisms that might explain a relationship between abdominal obesity and microalbuminuria are the presence of low-grade inflammation and endothelial dysfunction [42].

The strengths of our study include measuring UAC by radioimmunoassay in first morning urine samples, which eliminates the postural effects on albumin excretion. Participants were advised to limit physical activity the day before sample collection to reduce the likelihood of exerciseassociated albuminuria, and sample collection in the females was done when they were not menstruating. Tanner staging was performed, and data were collected on dietary intake, smoking habits, and level of physical activity, so we could 
TABLE 2: Metabolic syndrome and metabolic markers by urine albumin concentration group, stratified according to family history of diabetes.

\begin{tabular}{|c|c|c|c|}
\hline Metabolic syndrome and metabolic markers & $\begin{array}{c}\text { Normal UAC } \\
\begin{array}{c}(n=451) \\
\%\end{array} \\
\end{array}$ & $\begin{array}{c}\text { Elevated UAC } \\
(n=64) \\
\% \\
\end{array}$ & $p$ value $^{\ddagger}$ \\
\hline \multicolumn{4}{|l|}{ Without family history of diabetes $(n=422)$} \\
\hline Waist circumference $(\mathrm{cm}$, mean $\pm \mathrm{SD})$ & $74.9 \pm 10.3$ & $71.0 \pm 6.9$ & 0.013 \\
\hline Percent body fat $(\%$, mean \pm SD) & $28.9 \pm 11.1$ & $26.4 \pm 8.9$ & 0.120 \\
\hline Obesity & 7.9 & 3.7 & 0.403 \\
\hline Abdominal obesity & 13.9 & 5.6 & 0.124 \\
\hline High glucose & 9.8 & 7.4 & 0.803 \\
\hline High insulin & 15.3 & 7.4 & 0.147 \\
\hline High HOMA-IR ${ }^{\mathrm{a}}$ & 13.4 & 7.4 & 0.275 \\
\hline High blood pressure & 8.2 & 7.4 & 1.000 \\
\hline High triglycerides & 13.6 & 7.4 & 0.276 \\
\hline High total cholesterol & 7.1 & 3.7 & 0.558 \\
\hline Low HDL-C & 57.7 & 63.0 & 0.456 \\
\hline High LDL-C & 8.7 & 7.4 & 1.000 \\
\hline MetS & 7.9 & 3.7 & 0.403 \\
\hline Number of MetS components ${ }^{\mathrm{b}},($ mean $\pm \mathrm{SD})$ & $1.03 \pm 1.03$ & $0.91 \pm 0.76$ & 0.730 \\
\hline \multicolumn{4}{|l|}{ With family history of diabetes $(n=87)$} \\
\hline Waist circumference $(\mathrm{cm}$, mean $\pm \mathrm{SD})$ & $79.2 \pm 10.1$ & $76.8 \pm 9.4$ & 0.504 \\
\hline Percent body fat $(\%$, mean $\pm S D)$ & $34.2 \pm 11.6$ & $27.3 \pm 15.6$ & 0.225 \\
\hline Obesity & 21.8 & 11.1 & 0.678 \\
\hline Abdominal obesity & 26.9 & 44.4 & 0.272 \\
\hline High glucose & 5.1 & 44.4 & 0.003 \\
\hline High insulin & 23.1 & 11.1 & 0.411 \\
\hline High HOMA-IR ${ }^{\mathrm{a}}$ & 19.2 & 11.1 & 1.000 \\
\hline High blood pressure & 7.7 & 0.0 & 1.000 \\
\hline High triglycerides & 20.5 & 22.2 & 1.000 \\
\hline High total cholesterol & 11.5 & 11.1 & 1.000 \\
\hline Low HDL-C & 57.7 & 77.8 & 0.304 \\
\hline High LDL-C & 16.7 & 11.1 & 1.000 \\
\hline MetS & 16.7 & 22.2 & 0.650 \\
\hline Number of MetS components ${ }^{b},($ mean $\pm S D)$ & $1.18 \pm 1.09$ & $1.89 \pm 1.17$ & 0.069 \\
\hline
\end{tabular}

HDL-C: high-density lipoprotein-cholesterol, HOMA-IR: insulin resistance, LDL-C: low-density lipoprotein-cholesterol, MetS: metabolic syndrome, and UAC: urine albumin concentration.

${ }^{\ddagger}$ Chi square test, Fisher's exact test, Student's $t$-test, or Wilcoxon rank sum test.

${ }^{\mathrm{a}} \mathrm{HOMA}-\mathrm{IR}=$ fasting insulin $(\mu \mathrm{U} / \mathrm{mL}) \times$ fasting glucose $(\mathrm{mmol} / \mathrm{L}) / 22.5$.

${ }^{\mathrm{b}}$ Including abdominal obesity.

control for these potentially confounding variables. A limitation is that we did not measure the urine creatinine concentration and therefore could not correct for differences in urine volume. Hence, our measurement of UAC does not reflect the current standard for measurement of albuminuria, which is the albumin-to-creatinine ratio in the first morning urine sample [43]. Nevertheless, UAC is reported to have a sensitivity of $88.6 \%$ and a specificity of $88.9 \%$ for correctly classifying elevated albuminuria when compared with the $24 \mathrm{~h}$ urinary albumin excretion rate [44]. In addition, we performed only a single measurement of urinary albumin, which reduces precision relative to multiple measurements made over several days, thereby increasing the chance of misclassifying study participants [45].

\section{Conclusions}

We did not find an association between elevated UAC and MetS in nondiabetic Mexican adolescents. However, fasting hyperglycemia and the number of MetS components were associated with elevated UAC in those with a positive family history of diabetes. Also, female adolescents with abdominal obesity had elevated UAC. All these findings may reflect an increased risk for type 2 diabetes. 
TABLE 3: Crude and adjusted logistic regression analysis between elevated urine albumin concentration and metabolic syndrome and metabolic markers.

\begin{tabular}{|c|c|c|c|c|}
\hline $\begin{array}{l}\text { Metabolic } \\
\text { syndrome and } \\
\text { metabolic markers }\end{array}$ & $\mathrm{OR}_{\text {crude }}$ & $95 \% \mathrm{CI}$ & $\mathrm{OR}_{\text {adjusted }}$ & $95 \%$ CI \\
\hline Abdominal obesity & 0.65 & $0.28-1.47$ & 2.13 & $0.71-6.43$ \\
\hline High glucose & 1.43 & $0.64-3.20$ & 1.86 & $0.80-4.33$ \\
\hline High insulin & 0.52 & $0.22-1.24$ & 0.72 & $0.26-2.03$ \\
\hline High HOMA-IR & 0.61 & $0.25-1.48$ & 0.98 & $0.34-2.84$ \\
\hline $\begin{array}{l}\text { High blood } \\
\text { pressure }\end{array}$ & 0.77 & $0.26-2.24$ & 1.50 & $0.47-4.74$ \\
\hline High triglycerides & 0.60 & $0.25-1.46$ & 0.89 & $0.35-2.26$ \\
\hline $\begin{array}{l}\text { High total } \\
\text { cholesterol }\end{array}$ & 0.57 & $0.17-1.90$ & 0.78 & $0.22-2.75$ \\
\hline Low HDL-C & 1.42 & $0.82-2.45$ & 1.58 & $0.88-2.84$ \\
\hline High LDL-C & 0.91 & $0.37-2.23$ & 1.00 & $0.36-2.75$ \\
\hline MetS & 0.65 & $0.22-1.86$ & 1.97 & $0.55-7.10$ \\
\hline $\begin{array}{l}\text { Number of MetS } \\
\text { components }^{\mathrm{a}}\end{array}$ & 1.00 & $0.77-1.29$ & 1.39 & $1.00-1.95$ \\
\hline
\end{tabular}

HDL-C: high-density lipoprotein-cholesterol, HOMA-IR: insulin resistance, LDL-C: low-density lipoprotein-cholesterol, MetS: metabolic syndrome, and OR: odds ratio.

Models were adjusted by sex, sexual development, smoking, physical activity, protein intake, percent body fat, and family history of diabetes.

${ }^{\mathrm{a}}$ Including abdominal obesity.

TABLE 4: Associations between elevated urine albumin concentration and metabolic syndrome or metabolic markers, stratified according to obesity.

\begin{tabular}{|c|c|c|c|c|}
\hline Models & $\mathrm{OR}_{\text {crude }}$ & $95 \% \mathrm{CI}$ & $\mathrm{OR}_{\text {adjusted }}$ & $95 \% \mathrm{CI}$ \\
\hline \multicolumn{5}{|l|}{ Without obesity } \\
\hline Abdominal obesity & 1.12 & $0.42-3.00$ & 1.19 & $0.43-3.26$ \\
\hline High glucose & 1.75 & $0.73-4.19$ & 1.87 & $0.76-4.57$ \\
\hline High insulin & 0.75 & $0.28-1.97$ & 0.60 & $0.21-1.78$ \\
\hline High HOMA-IR & 0.76 & $0.26-2.23$ & 0.59 & $0.11-2.02$ \\
\hline High blood pressure & 0.79 & $0.23-2.69$ & 1.05 & $0.29-3.79$ \\
\hline High triglycerides & 0.71 & $0.27-1.88$ & 0.75 & $0.28-1.98$ \\
\hline High total cholesterol & 0.49 & $0.11-2.14$ & 0.50 & $0.11-2.22$ \\
\hline Low HDL-C & 1.52 & $0.87-2.66$ & 1.42 & $0.79-2.56$ \\
\hline High LDL-C & 0.77 & $0.26-2.24$ & 0.56 & $0.16-1.93$ \\
\hline MetS & 1.85 & $0.50-6.84$ & 2.08 & $0.55-7.85$ \\
\hline Number of MetS components ${ }^{\mathrm{a}}$ & 1.22 & $0.85-1.75$ & 1.23 & $0.84-1.79$ \\
\hline \multicolumn{5}{|l|}{ With obesity } \\
\hline Abdominal obesity & 0.19 & $0.01-2.59$ & 0.17 & $0.01-3.34$ \\
\hline High glucose & 1.27 & $0.11-15.23$ & 1.54 & $0.08-30.06$ \\
\hline High insulin & 0.22 & $0.02-2.62$ & 0.06 & $0.001-3.42$ \\
\hline High HOMA-IR & 0.97 & $0.08-11.54$ & 0.78 & $0.05-12.70$ \\
\hline High blood pressure & 1.59 & $0.13-19.27$ & 1.28 & $0.07-21.97$ \\
\hline High triglycerides & 0.60 & $0.05-7.03$ & 0.38 & $0.02-7.47$ \\
\hline High total cholesterol & 1.80 & $0.15-21.94$ & 1.47 & $0.10-20.82$ \\
\hline Low HDL-C ${ }^{b}$ & - & - & - & - \\
\hline High LDL-C & 5.67 & $0.47-68.28$ & 4.50 & $0.30-67.36$ \\
\hline MetS & 0.24 & $0.02-2.88$ & 0.05 & $0.001-2.48$ \\
\hline Number of MetS components ${ }^{\mathrm{a}}$ & 1.17 & $0.32-4.15$ & 0.99 & $0.20-4.86$ \\
\hline
\end{tabular}

HDL-C: high-density lipoprotein-cholesterol, HOMA-IR: insulin resistance, LDL-C: low-density lipoprotein-cholesterol, MetS: metabolic syndrome, and OR: odds ratio.

Models were adjusted by sex, sexual development, smoking, physical activity, protein intake and history of type 2 diabetes.

${ }^{a}$ Including abdominal obesity.

${ }^{\mathrm{b}} \mathrm{OR}$ was not calculated because of the small sample size for one comparison group in these cells. 
TABLE 5: Associations between elevated urine albumin concentration and metabolic syndrome or metabolic markers, stratified according to family history of diabetes.

\begin{tabular}{|c|c|c|c|c|}
\hline Models & $\mathrm{OR}_{\text {crude }}$ & $95 \% \mathrm{CI}$ & $\mathrm{OR}_{\text {adjusted }}$ & $95 \% \mathrm{CI}$ \\
\hline \multicolumn{5}{|l|}{ Without family history of diabetes } \\
\hline Abdominal obesity $^{\mathrm{a}}$ & 0.25 & $0.06-1.08$ & 0.39 & $0.12-1.32$ \\
\hline High glucose $\mathrm{e}^{\mathrm{b}}$ & 0.58 & $0.17-1.94$ & 0.83 & $0.28-2.47$ \\
\hline High insulin $^{c}$ & 0.35 & $0.10-1.15$ & 0.72 & $0.23-2.27$ \\
\hline High HOMA-IR ${ }^{c}$ & 0.41 & $0.12-1.35$ & 0.98 & $0.30-3.21$ \\
\hline High blood pressure $^{c}$ & 0.96 & $0.32-2.84$ & 1.87 & $0.57-6.17$ \\
\hline High triglycerides $^{c}$ & 0.40 & $0.12-1.32$ & 0.75 & $0.25-2.26$ \\
\hline High total cholesterol $^{\mathrm{c}}$ & 0.26 & $0.03-1.98$ & 0.69 & $0.15-3.17$ \\
\hline Low HDL-C ${ }^{c}$ & 1.35 & $0.73-2.48$ & 1.35 & $0.72-2.53$ \\
\hline High LDL-C ${ }^{c}$ & 0.65 & $0.19-2.23$ & 1.21 & $0.39-3.78$ \\
\hline MetS $^{d}$ & 0.23 & $0.03-1.75$ & 1.42 & $0.26-7.78$ \\
\hline Number of MetS components ${ }^{\mathrm{de}}$ & 0.88 & $0.65-1.19$ & 1.16 & $0.79-1.70$ \\
\hline \multicolumn{5}{|l|}{ With family history of diabetes } \\
\hline Abdominal obesity ${ }^{\mathrm{a}}$ & 2.71 & $0.62-11.85$ & 3.19 & $0.68-15.03$ \\
\hline High glucose $\mathrm{e}^{\mathrm{b}}$ & 11.10 & $1.93-63.85^{*}$ & 9.81 & $1.62-59.43^{*}$ \\
\hline High insulin $^{c}$ & 0.48 & $0.05-4.13$ & 0.64 & $0.06-6.82$ \\
\hline High HOMA-IR ${ }^{c}$ & 0.60 & $0.07-5.25$ & 0.92 & $0.08-10.57$ \\
\hline High blood pressure $^{\mathrm{f}}$ & - & - & - & - \\
\hline High triglycerides $^{c}$ & 1.29 & $0.24-7.01$ & 2.01 & $0.28-14.45$ \\
\hline High total cholesterol $^{\mathrm{c}}$ & 1.10 & $0.12-9.96$ & 1.93 & $0.18-21.25$ \\
\hline Low HDL-C ${ }^{c}$ & 2.20 & $0.42-11.59$ & 4.94 & $0.70-34.78$ \\
\hline High LDL-C ${ }^{c}$ & 0.71 & $0.08-6.31$ & 0.91 & $0.09-9.07$ \\
\hline $\operatorname{Met}^{\mathrm{d}}$ & 1.67 & $0.30-9.19$ & 6.32 & $0.58-68.90$ \\
\hline Number of MetS components ${ }^{\mathrm{de}}$ & 1.69 & $0.94-3.04$ & 4.48 & $1.51-13.32^{* *}$ \\
\hline
\end{tabular}

HDL-C: high-density lipoprotein-cholesterol, HOMA-IR: insulin resistance, LDL-C: low-density lipoprotein-cholesterol, MetS: metabolic syndrome, and OR: odds ratio.

${ }^{a}$ Adjusted by sex, sexual development, smoking, physical activity, and protein intake.

${ }^{\mathrm{b}}$ Adjusted by physical activity, protein intake and percent body fat.

${ }^{\mathrm{c}}$ Adjusted by sex, sexual development, smoking, physical activity, protein intake and percent body fat.

${ }^{\mathrm{d}}$ Adjusted by sex, sexual development, physical activity, protein intake and percent body fat.

${ }^{\mathrm{e}}$ Including abdominal obesity.

${ }^{\mathrm{f}}$ OR was not calculated because of the small sample size for one comparison group in these cells.

${ }^{*} p$ value $<0.05,{ }^{* *} p$ value $<0$.

\section{Conflict of Interests}

The authors declare that there is no conflict of interests regarding publication of this paper.

\section{Acknowledgments}

This research was supported by the National Council of Science and Technology (CONACYT), Grant 37951-M, and CONACYT Scholarship 159083. The authors thank the students, their parents, the school personnel, and those involved in the data collection.

\section{References}

[1] W. Bakker, E. C. Eringa, P. Sipkema, and V. W. M. Van Hinsbergh, "Endothelial dysfunction and diabetes: roles of hyperglycemia, impaired insulin signaling and obesity," Cell and Tissue Research, vol. 335, no. 1, pp. 165-189, 2009.
[2] A. J. Corona, D. R. Martenez, M. H. Avila et al., "Microalbuminuria as a predictor of myocardial infarction in a Mexican population: the Mexico City Diabetes Study," Kidney International, Supplement, vol. 68, no. 97, pp. S34-S39, 2005.

[3] A. H. Brantsma, S. J. L. Bakker, D. de Zeeuw, P. E. de Jong, and R. T. Gansevoort, "Urinary albumin excretion as a predictor of the development of hypertension in the general population," Journal of the American Society of Nephrology, vol. 17, no. 2, pp. 331-335, 2006.

[4] J. Chen, P. Muntner, L. L. Hamm et al., "The metabolic syndrome and chronic kidney disease in U.S. adults," Annals of Internal Medicine, vol. 140, no. 3, pp. 167-174, 2004.

[5] L. Mykkänen, S. M. Haffner, J. Kuusisto, K. Pyorälä, and M. Laakso, "Microalbuminuria precedes the development of NIDDM," Diabetes, vol. 43, no. 4, pp. 552-557, 1994.

[6] P. H. Lane, "Diabetic kidney disease: impact of puberty," The American Journal of Physiology-Renal Physiology, vol. 283, no. 4, pp. F589-F600, 2002. 
[7] N. H. Kim, M. E. Pavkov, W. C. Knowler et al., "Predictive value of albuminuria in American Indian youth with or without type 2 diabetes," Pediatrics, vol. 125, no. 4, pp. e844-e851, 2010.

[8] S. Nguyen, C. McCulloch, P. Brakeman, A. Portale, and C.-Y. Hsu, "Being overweight modifies the association between cardiovascular risk factors and microalbuminuria in adolescents," Pediatrics, vol. 121, no. 1, pp. 37-45, 2008.

[9] J. Coresh, D. Byrd-Holt, B. C. Astor et al., "Chronic kidney disease awareness, prevalence, and trends among U.S. adults, 1999 to 2000," Journal of the American Society of Nephrology, vol. 16, no. 1, pp. 180-188, 2005.

[10] C. A. Jones, M. E. Francis, M. S. Eberhardt et al., "Microalbuminuria in the US population: third national health and nutrition examination survey," American Journal of Kidney Diseases, vol. 39, no. 3, pp. 445-459, 2002.

[11] G. E. Duncan, S. M. Li, and X.-H. Zhou, "Prevalence and trends of a metabolic syndrome phenotype among U.S. adolescents, 1999-2000," Diabetes Care, vol. 27, no. 10, pp. 2438-2443, 2004.

[12] E. S. Ford, C. Li, G. Zhao, W. S. Pearson, and A. H. Mokdad, "Prevalence of the metabolic syndrome among U.S. adolescents using the definition from the international diabetes federation," Diabetes Care, vol. 31, no. 3, pp. 587-589, 2008.

[13] E. H. Castillo, G. Borges, J. O. Talavera et al., "Body mass index and the prevalence of metabolic syndrome among children and adolescents in two Mexican populations," Journal of Adolescent Health, vol. 40, no. 6, pp. 521-526, 2007.

[14] World Health Organization, Definition, Diagnosis, and Classification of Diabetes Mellitus and Its Complications: Report of a WHO Consultation. Part 1. Diagnosis and Classification of Diabetes Mellitus, WHO/NCD/NCS/99.2, World Health Organization, Geneva, Switzerland, 1999.

[15] P. Zimmet, G. K. M. M. Alberti, F. Kaufman et al., "The metabolic syndrome in children and adolescents-an IDF consensus report," Pediatric Diabetes, vol. 8, no. 5, pp. 299-306, 2007.

[16] M. Franciosi, F. Pellegrini, M. Sacco et al., "Identifying patients at risk for microalbuminuria via interaction of the components of the metabolic syndrome: a cross-sectional analytic study," Clinical Journal of the American Society of Nephrology, vol. 2, no. 5, pp. 984-991, 2007.

[17] T. S. Burgert, J. Dziura, C. Yeckel et al., "Microalbuminuria in pediatric obesity: prevalence and relation to other cardiovascular risk factors," International Journal of Obesity, vol. 30, no. 2, pp. 273-280, 2006.

[18] K. Csernus, E. Lanyi, E. Erhardt, and D. Molnar, "Effect of childhood obesity and obesity-related cardiovascular risk factors on glomerular and tubular protein excretion," European Journal of Pediatrics, vol. 164, no. 1, pp. 44-49, 2005.

[19] C. Invitti, C. Maffeis, L. Gilardini et al., "Metabolic syndrome in obese Caucasian children: prevalence using WHO-derived criteria and association with nontraditional cardiovascular risk factors," International Journal of Obesity, vol. 30, no. 4, pp. 627633, 2006.

[20] C. M. Forsblom, J. G. Eriksson, A. V. Ekstrand, A.-M. Teppo, M.-R. Taskinen, and L. C. Groop, "Insulin resistance and abnormal albumin excretion in non-diabetic first-degree relatives of patients with NIDDM," Diabetologia, vol. 38, no. 3, pp. 363-369, 1995.

[21] T. Lohman, A. Roche, and R. Martorell, Anthropometric Standardization Reference Manual, Human Kinetics Books, Champaign, Ill, USA, 1998.
[22] J. M. Hamili, S. Hadjadj, V. Aboyans et al., "Microalbuminuria and urinary albumin excretion: French clinical practice guidelines," Diabetes \& Metabolism, vol. 33, no. 4, pp. 303-309, 2007.

[23] National Cholesterol Education Program (NCEP), "highlights of the report of the expert panel on blood cholesterol levels in children and adolescents," Pediatrics, vol. 89, no. 3, pp. 495-501, 1992.

[24] B. García Cuartero, C. García Lacalle, C. Jiménez Lobo et al., "Índice HOMA y QUICKI, insulina y péptido C en niños sanos. Puntos de corte de riesgo cardiovascular," Anales de Pediatría, vol. 66, no. 5, pp. 481-490, 2007.

[25] T. J. Cole, M. C. Bellizzi, K. M. Flegal, and W. H. Dietz, "Establishing a standard definition for child overweight and obesity worldwide: international survey," British Medical Journal, vol. 320, no. 7244, pp. 1240-1243, 2000.

[26] M. H. Slaughter, T. G. Lohman, R. A. Boileau et al., "Skinfold equations for estimations of body fatness in children and youth," Human Biology, vol. 60, no. 5, pp. 709-723, 1988.

[27] S. E. Marcus, G. A. Giovino, J. P. Pierce, and Y. Harel, "Measuring tobacco use among adolescents," Public Health Reports, vol. 108, supplement 1, pp. 20-24, 1993.

[28] B. Hernández, S. L. Gortmaker, N. M. Laird, G. A. Colditz, S. Parra-Cabrera, and K. E. Peterson, "Validez y reproducibilidad de un cuestionario de actividad e inactividad física para escolares de la ciudad de México," Salud Pública de México, vol. 42, no. 4, pp. 315-323, 2000.

[29] M. Hernández-Avila, I. Romieu, S. Parra, J. Hernández-Avila, H. Madrigal, and W. Willett, "Validity and reproducibility of a food frequency questionnaire to assess dietary intake of women living in Mexico City," Salud Publica de Mexico, vol. 40, no. 2, pp. 133-140, 1998.

[30] N. M. Schlossberger, R. A. Turner, and C. E. Irwin Jr., "Validity of self-report of pubertal maturation in early adolescents," Journal of Adolescent Health, vol. 13, no. 2, pp. 109-113, 1992.

[31] C. A. Peralta, Y. Li, C. Wassel et al., "Differences in albuminuria between Hispanics and whites: an evaluation by genetic ancestry and country of origin: the multi-ethnic study of atherosclerosis," Circulation: Cardiovascular Genetics, vol. 3, no. 3, pp. 240-247, 2010.

[32] G. Leoncini, E. Ratto, F. Viazzi et al., "Metabolic syndrome is associated with early signs of organ damage in nondiabetic, hypertensive patients," Journal of Internal Medicine, vol. 257, no. 5, pp. 454-460, 2005.

[33] S. M. Haffner, C. Gonzales, R. A. Valdez et al., "Is microalbuminuria part of the prediabetic state? The Mexico City Diabetes study," Diabetologia, vol. 36, no. 10, pp. 1002-1006, 1993.

[34] J. B. Meigs, R. B. D’Agostino Sr., D. M. Nathan, N. Rifai, and P. W. F. Wilson, "Longitudinal association of glycemia and microalbuminuria: the Framingham Offspring Study," Diabetes Care, vol. 25, no. 6, pp. 977-983, 2002.

[35] R. J. Tapp, J. E. Shaw, B. Balkau et al., "Albuminura is evident in the early stages of diabetes onset: results from the Australian Diabetes, Obestiy and Lifestyle Study (AusDiab)," American Journal of Kidney Diseases, vol. 44, no. 5, pp. 792-798, 2004.

[36] P. W. F. Wilson, J. B. Meigs, L. Sullivan, C. S. Fox, D. M. Nathan, and R. B. D'Agostino Sr., "Prediction of incident diabetes mellitus in middle-aged adults: the framingham offspring study," Archives of Internal Medicine, vol. 167, no. 10, pp. 1068-1074, 2007.

[37] A. M. Annis, M. S. Caulder, M. L. Cook, and D. Duquette, "Family history, diabetes, and other demographic and risk 
factors among participants of the National Health and Nutrition Examination Survey 1999-2002," Preventing Chronic Disease, vol. 2, no. 2, pp. 1-12, 2005.

[38] J. L. Vassy, P. DasMahapatra, J. B. Meigs et al., "Genotype prediction of adult type 2 diabetes from adolescence in a multiracial population," Pediatrics, vol. 130, no. 5, pp. e1235e1242, 2012.

[39] K. C. Copeland, P. Zeitler, M. Geffner et al., "Characteristics of adolescents and youth with recent-onset type 2 diabetes: the TODAY cohort at baseline," The Journal of Clinical Endocrinology \& Metabolism, vol. 96, no. 1, pp. 159-167, 2011.

[40] I. S. Hoffmann, E. Jimenez, and L. X. Cubeddu, "Urinary albumin excretion in lean, overweight and obese glucose tolerant individuals: Its relationship with dyslipidaemia, hyperinsulinaemia and blood pressure," Journal of Human Hypertension, vol. 15, no. 6, pp. 407-412, 2001.

[41] P. K. Chandie Shaw, S. P. Berger, M. Mallat, M. Frölich, F. W. Dekker, and T. J. Rabelink, "Central obesity is an independent risk factor for albuminuria in nondiabetic South Asian subjects," Diabetes Care, vol. 30, no. 7, pp. 1840-1844, 2007.

[42] S. C. Satchell and J. E. Tooke, "What is the mechanism of microalbuminuria in diabetes: a role for the glomerular endothelium?" Diabetologia, vol. 51, no. 5, pp. 714-725, 2008.

[43] M. E. Molitch, R. A. DeFronzo, M. J. Franz et al., "Nephropathy in diabetes," Diabetes Care, vol. 27, supplement 1, pp. S79-S83, 2004.

[44] T. Zelmanovitz, J. L. Gross, J. R. Oliveira, A. Paggi, M. Tatsch, and M. J. Azevedo, "The receiver operating characteristics curve in the evaluation of a random urine specimen as a screening test for diabetic nephropathy," Diabetes Care, vol. 20, no. 4, pp. 516519, 1997.

[45] D. J. F. Rowe, H. Bagga, and P. B. Betts, "Normal variations in rate of albumin excretion and albumin to creatinine ratios in overnight and daytime urine collections in non-diabetic children," British Medical Journal, vol. 291, no. 6497, pp. 693694, 1985. 


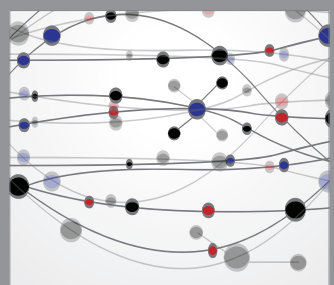

The Scientific World Journal
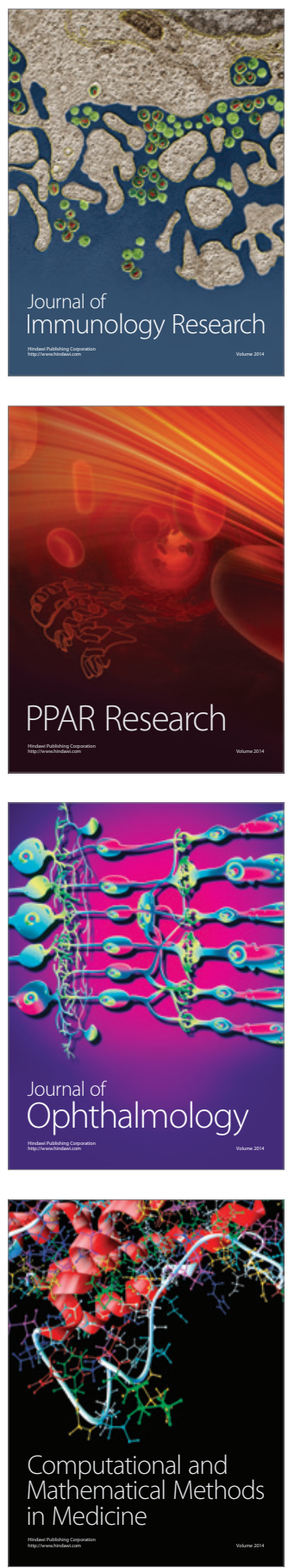

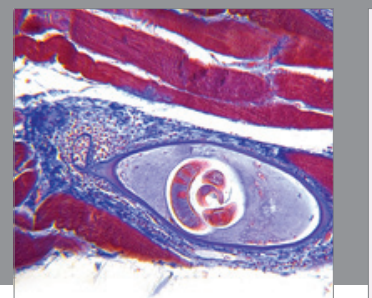

Gastroenterology

Research and Practice
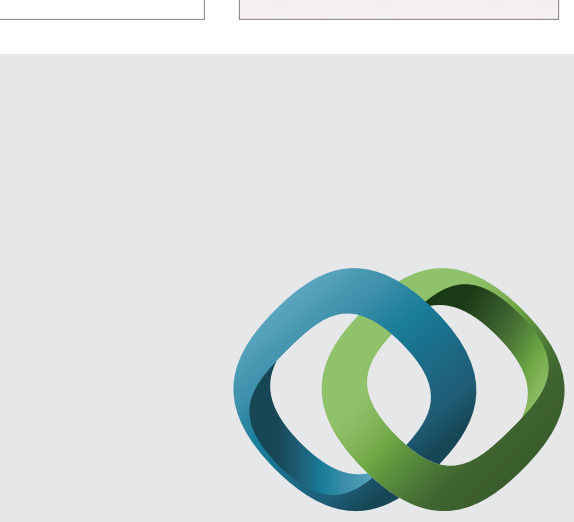

\section{Hindawi}

Submit your manuscripts at

http://www.hindawi.com
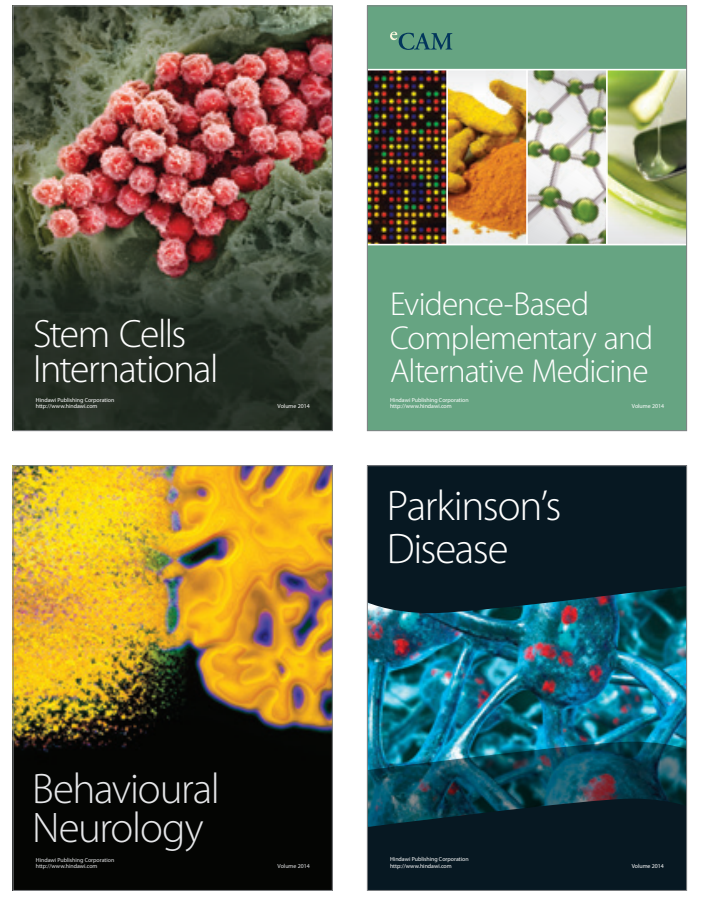
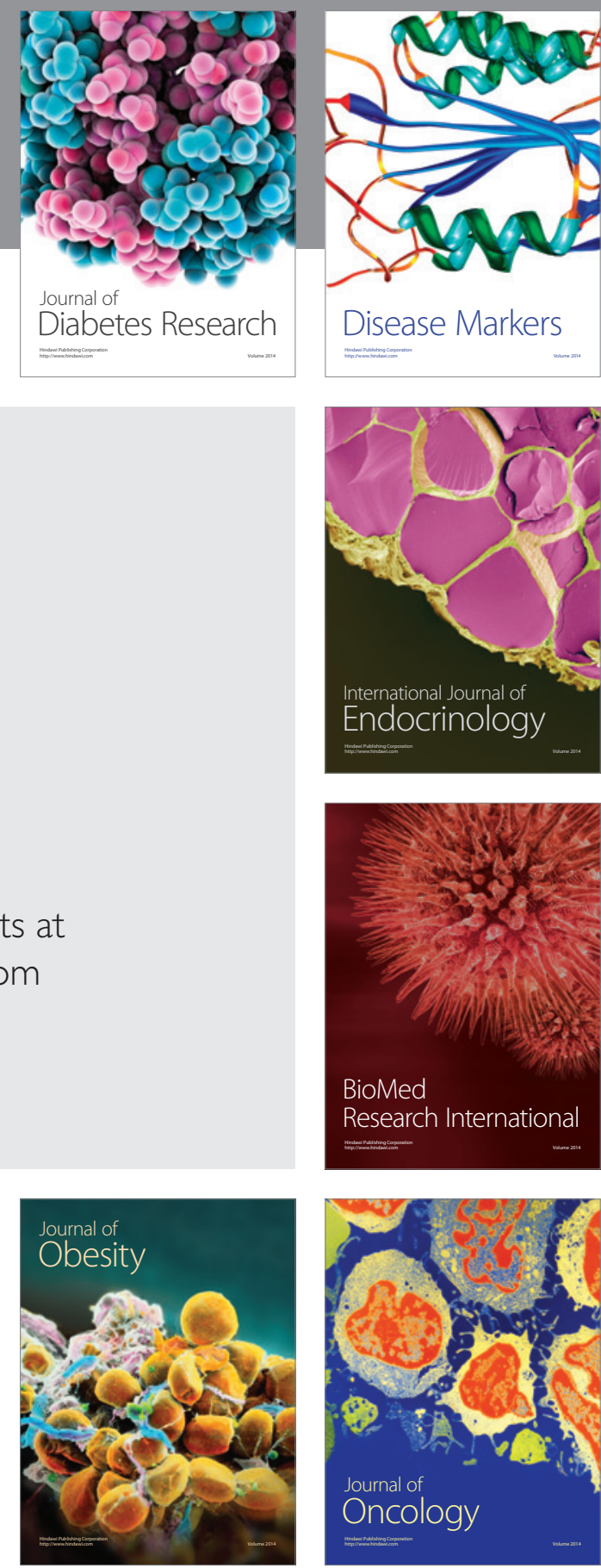

Disease Markers
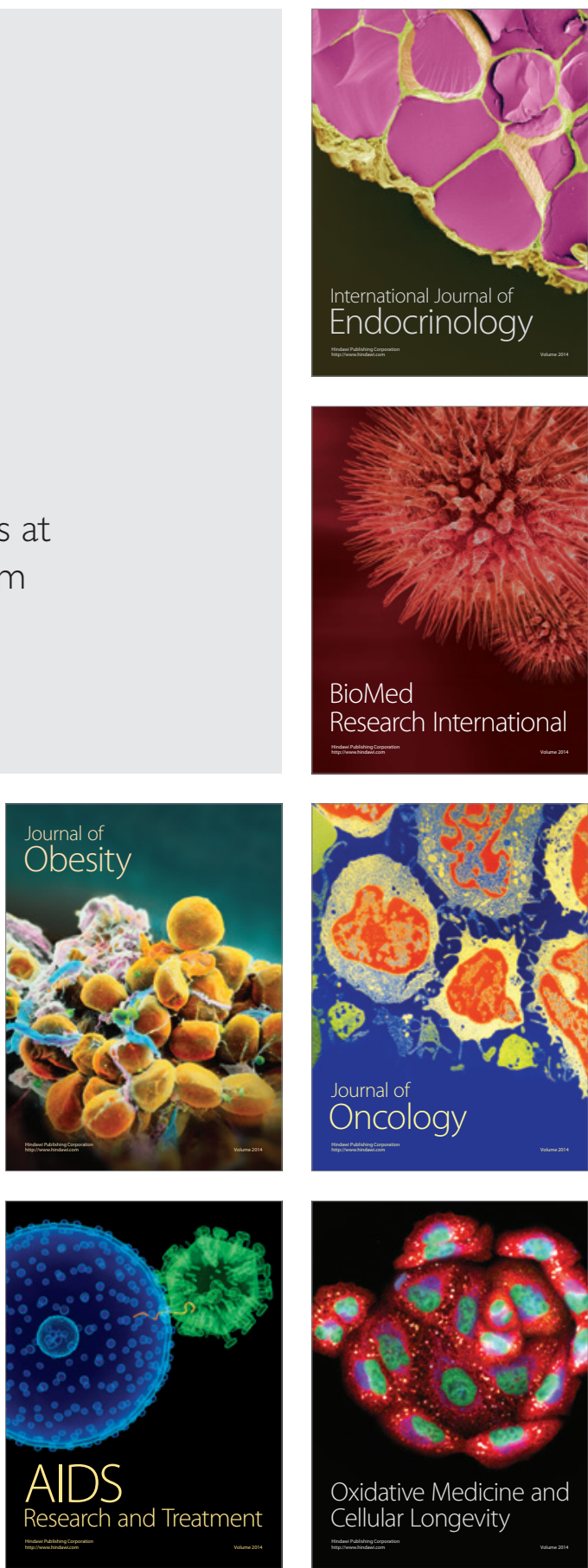